\title{
Choreographing Difference: \\ The (Body) Politics of Banaban Dance
}

Katerina Martina Teaiwa

In London, during the protracted court case involving Banaban compensation claims for the destruction of their Ocean Island homeland by phosphate mining, a daily newspaper posed the question: "Who are these Banaban people anyway?" A group of Banaban dancers were in London at the time and they responded to the question. They announced a performance of music and dance with the simple and powerful statement: "We, the Banabans, are the people who dance like this. ..."

JenNifer SHENNAN, "Approaches to THE STUdY of Dance in OCEANia”

\begin{abstract}
$\mathrm{T}_{\mathrm{his}}$ his article represents aspects of research conducted between I999 and 2002 in Australia, New Zealand, Fiji, and Kiribati, and during two brief trips to Rabi Island in 2007-2008. It explores body movement as an expression of historical and postcolonial identities and, more specifically, focuses on the relationships between Banabans and Gilbertese (I-Kiribati), in terms of what I understand as the Banaban production of difference through dance. This Banaban mode of understanding identity and history in terms of difference is shaped by a strategic approach to representing the past. That past is marked by a particularly difficult experience of having a significant portion of indigenous Banaban land removed through phosphate mining between I900 and I980 (figure I). The phosphate was converted into superphosphate fertilizer and used intensively on Australian and New Zealand farms (see Teaiwa 2005a). For Banabans it was this loss of land through mining, as well as a particularly charged cultural and political situation with the Gilbert Islands people and government,
\end{abstract}

The Contemporary Pacific, Volume 24, Number I, 65-94

(C) 2012 by University of Hawai'i Press 
that gave rise to "Banaban dance" in their new home of Rabi in Fiji. This new style is now recognized as an established and unique Pacific dance tradition.

Banaban history has unfolded in such a way that Banabans have been forced to selectively remember their past. Noted Pacific scholar and novelist Albert Wendt wrote:

A society is what it remembers; we are what we remember; I am what I remember; the self is a trick of memory. Physically and genetically we are the unfolding of our DNA, the programmed memory of our genes, which, incidentally, can now be altered through biotechnology. And, as all historians know, history has everything to do with memory and remembering: history is the remembered tightrope that stretches across the abyss of all that we have forgotten. (1987, 79 ; italics in original)

One such historical thread for Banabans involves their relationships with their closest relatives, the I-Kiribati. ${ }^{1}$ The kinship between these groups is politically charged and contorted by the impact of phosphate mining on each culture's sense of its past, present, and future. This fraught relationship brings into relief the intra-Pacific politics of postcolonial identities

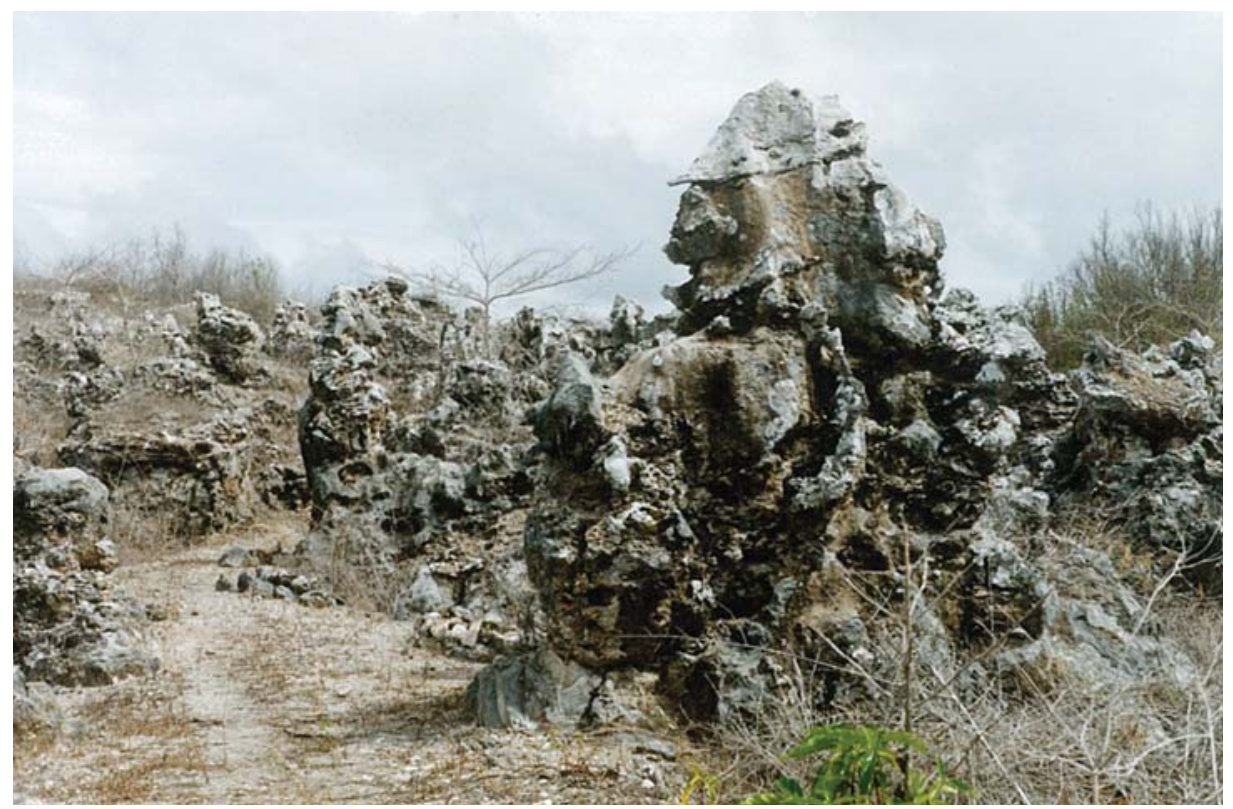

FIGURE I The limestone pinnacles that remain from phosphate mining. Banaba, April 2000. Photo by Katerina Teaiwa. 
and related social and political practices (see Teaiwa 2007). When I began this research in 1999, my aim was to examine the impact of the British Phosphate Commissioners (BPC) on the island of Banaba in Kiribati and to analyze how the industry affected the lives of both the Banaban landowners and the Gilbertese laborers.

The six-square-kilometer island has been inhabited for over two thousand years, and centuries before the mining began in 1900, waves of Gilbertese migrants, including my own ancestors, settled on Banaba. In I900, the indigenous Banabans spoke the Kiribatese (Gilbertese) language with a few words and phrases remaining from a more ancient language (see Maude 1994; Silverman 197I; Sigrah and King 200I). Soon after mining commenced, Banaba was annexed to the protectorate of the Gilbert and Ellice Islands, which the British had established in I 892. Profits from the mining industry financed the administration of the colony, and the company (known in various stages as the Pacific Islands Company and the Pacific Phosphate Company before it became the BPC) also imported significant numbers of workers from both island groups. During the eighty years of mining, relations between Banabans and Gilbertese pivoted around kinship and class distinctions. Banabans were the often precariously positioned landowners, while Gilbertese, as lowly miners, saw their earlier relationship as kin systematically unraveled due to the economic and political imperatives of mining and the broader agenda of the British Empire.

In 1945 at the end of World War II, the BPC, run jointly by the governments of Britain, Australia, and New Zealand, moved the Banabans to Rabi Island in Fiji. In the I970s the British government began preparing to dispose of its Pacific colonies, and Banaba was to be incorporated into an independent Gilbert Islands. The Banabans strongly felt that they deserved their own independence and fought the Gilbert Islands government over this plan, arguing that their culture was different from that of the Gilbertese. In spite of their efforts, in 1979 Banaba became one of the many islands in the new Republic of Kiribati. Reserve funds, generated from the income from the extraction and shipping of twenty million tons of phosphate under British colonial administration, served as two giant savings accounts with which to launch both independent states of Tuvalu and Kiribati (see Williams and Macdonald 1985 and Van Trease 1993). These accounts are now worth hundreds of millions of dollars and are earning interest in banks around the globe.

My original plan had been to read the relationship between Banabans 
and Gilbertese alongside their relationship with the British administration and the Australian and New Zealand BPC management. My methodology was to be a combination of archival work in Melbourne, Canberra, and Adelaide in Australia, and Auckland and Wellington in New Zealand, with participant observation on the islands of Rabi in Fiji, and Tarawa, Tabiteuea, and Banaba in Kiribati (figure 2; see Teaiwa 2002 and 2004). All nine locations were directly connected through the phosphate-mining venture, and I hoped that my research would reveal the exploitative nature of the mining company and the reliance of antipodean agriculture on small Pacific Islands. I was particularly focused on the discourse of kawa (pity) that pervaded the lives of the Banaban communities displaced by the industry, and I planned to use a political-economy lens, combined with ethnographic research, to deconstruct kawa in relation to land and mining. However, as is common in most research projects, things did not turn out exactly the way I had imagined.

\section{Body Writing Movement}

Susan Leigh Foster began her reflections on choreographing history thus:

Sitting in this chair, squirming away from the glitches, aches, low-grade tensions reverberating in neck and hip, staring unfocused at some space between here and the nearest objects, shifting again, listening to my stomach growl, to the clock ticking, shifting, stretching, settling, turning-I am a body writing, I am a bodily writing. (Foster 1995,3 )

Three things dramatically transformed my research project during the period of fieldwork ${ }^{2}$ - the digital video camera, the fact that I am of both Banaban and Kiribati descent, and dance (see Teaiwa 2005 b). My father grew up on Rabi and travels there regularly, but I was primarily raised in Suva, the capital of Fiji. My African-American mother has a strong musical and performing arts background and encouraged similar interests in her three daughters. Despite the lack of teachers and performing arts schools, we managed to gain basic movement literacy in ballet, modern dance, and gymnastics along with a range of Chinese and Pacific Island dances. My younger sister and I continued with ballet, jazz, and modern dance at university, and I eventually became a founding member of the Oceania Dance Theatre at the Oceania Centre for Arts and Culture in Suva. ${ }^{3}$ Because English is our first language and my Kiribatese-language 


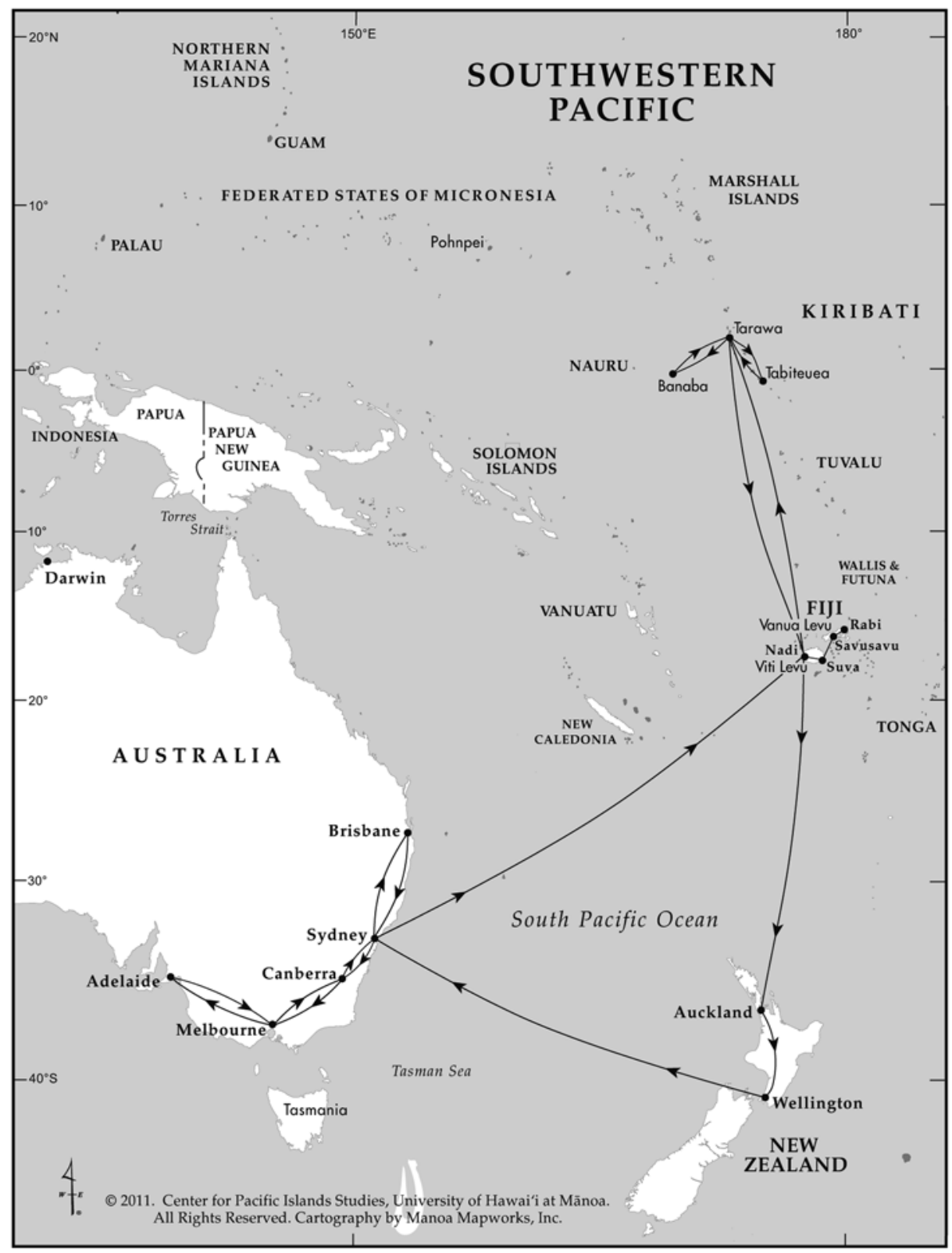

FIGURE 2 My research itinerary between I 999 and 2002. 
skills leave much to be desired, during the research period-in between interviews with former phosphate miners and Banaban elders-I kept turning to dance as a way to establish rapport with people.

Between Tarawa and Tabiteuea, when people found out that I was a contemporary Pacific dancer who knew the choreography to the very popular song "Pate Pate" by the Tokelauan-New Zealand band Te Vaka, I was regularly called upon to teach or perform. ${ }^{4} \mathrm{I}$, in turn, began to learn Kiribati dances such as te buki, which incorporates large, sweeping hip movements, and te bino, an ancient sitting dance. Dance became an acceptable medium through which to connect with people who otherwise regarded me as a conceptual anomaly-an I-Kiribati woman who did not speak the language and did not understand Kiribati customs. ${ }^{5}$

Despite this cultural gap, I found that I was familiar with people's embodied ways of interacting and with shared patterns of behavior and bodily comportment, because they were similar to what I had been raised with in Fiji and had experienced in various Banaban and Kiribati gatherings in Suva. Recognizing this, I began to consciously observe the ways in which people moved and physically interacted with each other and with their environments. At the time, I did not approach this systematically, paying close attention to all cultural practices, but rather gathered raw footage and made random notes about body movement in everyday life and dance, all of which I would reflect on months later.

For example, using my digital video camera, which was a core research tool, I looked less and less for obvious action or verbal exposition and let the camera follow more mundane, everyday activities. These movements took on charged significance as I began to pay attention to everything from a shoulder shrug or nodding head, to the way the fingers curled over the side of a canoe, or to how a woman's strong hands rolled and kneaded a piece of dough into fat round doughnuts over a two-hour period.

Back in Fiji, I especially noticed how my male cousins on Rabi would go out fishing in their canoes and spend hours with a hand-line, releasing its weighted length into the ocean and swiftly reeling it back in with a rapid but graceful swinging movement of the arms. On any given evening there is a crowd of canoes in the ocean between Rabi, Taveuni, Kioa, and Vanua Levu, with twenty or so young men all releasing and reeling in their handlines with this exact same set of arm movements. I began to realize that men's dance back in Kiribati is often a direct illustration of fishing stories and techniques.

As Susan Leigh Foster wrote: 
Once the historian's body recognizes value and meaning in kinesthesia, it cannot dis-animate the physical action of past bodies it has begun to sense. . . .

the writing body listens and waits as fragments of past bodies shimmer and then vanish." ( 1995,7 ; italics in original)

After my ethnographic work in the islands, I also found I could no longer read the hundreds of BРС archival documents I had transcribed or photocopied in the National Archives of Australia without trying to imagine each personality and human image as a living body. I wanted to know how they felt, what kinds of aches and pains and bursts of energy they experienced; how they moved with respect to each other, how they brushed past coconut tree trunks or leaned against the sides of buildings; how bodies felt in the hot sun while mining the rock face with pick and shovel, without shoes, without masks, and without hard hats. I could not look at any of the 380 BPC photographs copied in Melbourne without imagining the black-and-white scenes bursting into life in full Technicolor. ${ }^{6}$

Each site-Banaba, Tabiteuea, Tarawa, Canberra, Melbourne, Wellington, Rabi, Suva, and Adelaide-became a location in which to encounter a partial perspective of Banaban and I-Kiribati history, populated by diverse bodies (Teaiwa 2004). Each location also demanded its own regimes of corporeal knowledge: sitting silently on a chair in the archives turning pages, balancing myself on a motor canoe between Tabiteuea north and south or on a yacht between Tarawa and Banaba, sitting cross-legged in the meeting house (mwaneaba) for hours, and learning to move my head, eyes, and arms like a frigate bird in my aunty's house at Tanaeang.

These partial perspectives, these different sets of body movements and relationships with the physical environment in diverse locations, did not constitute a typical, complete research product; rather, they were fragments of an infinite number of possible approaches and experiences to human history and culture in the Pacific, with some resonances and indeed some dissonances between deeply connected sites and peoples. Later I would find support for translating some of my experiences into appropriate words in the works of Albert Wendt, Epeli Hau'ofa, Greg Dening, Teresia Teaiwa, Donna Haraway, George Marcus, Kamala Visweswaran, Kirin Narayan, and Trinh T Minh-Ha, as well as in Ruth Behar and Deborah A Gordon's Women Writing Culture (1995). These authors provided a creative and interdisciplinary intellectual genealogy in which I could locate my work.

"Writing up," however, wasn't my only challenge. Through my trav- 
els to the various islands and because I was unable to fall back on my normally strong verbal skills, I had experienced an ontological shift that increasingly favored embodied knowledge. My lifetime of learning and performing dances-assumed up to this point to be completely irrelevant to the completion of a $\mathrm{PhD}$ in the social sciences or humanities and to academia in general-became relevant. Moving Pacific bodies had agency and were foregrounded as major vehicles for, and expressions of, history, culture, politics, and identity. Such a growing realization did not sit well within the discursively heavy space of the academy in which I was located.

Writing about bodies is not the same as imagining or experiencing the world or history from the perspective of a writing or moving body. There was a tension between my increasing corporeal awareness and the demands of reading, writing, typing, and mentally constructing a piece of academic work while sitting in a chair for hours in a tiny office with the door shut. I would look around my space and notice that it was three by two and a bit meters. I imagined a view of my desk from the doorway and sometimes observed that I had not really moved my shoulders, back, hips, or legs for up to two hours. All the movement in my body was concentrated in my hands, which were strumming away at the keys while my wrists remained fixed to a narrow band of desk in front of the computer keyboard. My right index finger would lift and press down, followed rapidly by my middle finger and thumb. My left hand repeated the motion.

In my attempts to make sense of dance and corporeality within the context of the multi-sited research I had already conducted, the field of dance studies provided a bridge between the epistemological and ontological gaps-between Pacific studies and body movement. Most dance studies scholars would agree that exploring meaning in everyday or ritualized movements requires more than just an attention to the body, to its techniques and vocabulary, or to knowledge of how movements change over time. I found that the small but established field of Pacific ethnomusicology to which scholars usually turn for the Pacific performing arts, with some exceptions often ignored dance.

For example, Adrienne Kaeppler's pioneering work in Pacific dance ethnology offers clear theoretical and methodological approaches for analyzing a structured movement system-dance as object-placed within the context of a cultures' underlying poetic metaphors and values (Kaeppler 1972). This structuralist approach, however, works better with dance topic and tools already in hand and is more difficult to apply when movement is discovered as meaningful in the middle of a research project. Jen- 
nifer Shennan's somewhat humorous assessment of dance ethnology and dance studies in the Pacific in I98 I highlights the disconnection between the context and lived reality of dance in Oceania, particularly in terms of the experiences of dancing Pacific Islanders, and the methodology offered to researchers at the time. She wrote: "In crash-course style to prepare field workers in dance ethnology, a checklist has been seriously offered to anthropologists going into the field. When faced by people dancing fast, it tells them what to look for before the dancing stops. The question of whether the dancer is carrying an umbrella or not is No. I 20 on this list; No. 65 asks whether the dancer is wearing blocked toe shoes; No. 70 a bustle and so on. An unkind cartoonist would have a wonderful time assembling from all these questions an identikit portrait of Oceania's average dancer" (Shennan I98I, I93).

Shennan also assessed the limitations of both her own work on Māori dance and Kaeppler's work on Tongan dance, pointing out that the gender of the researcher limits access to certain styles and genres (Shennan I98I, 200). The following principles of a particularly useful dance studies methodology are excerpted and adapted from dance ethnologist Deidre Sklar's "Five Premises for a Culturally Sensitive Approach to Dance" (200I, $30-3 \mathrm{I}$; italics in original): ${ }^{7}$

I. Movement knowledge is a kind of cultural knowledge. To speak of movement as a way of knowing implies that the way people move is as much a clue to who they are as the way they speak. ...

2. Movement knowledge is conceptual and emotional as well as kinaesthetic.... [It addresses] life's "large questions": Where do I belong in the world? How do human beings behave? Where do I come from and with whom do I go through life? What do I value? ...

3. Movement knowledge is intertwined with other kinds of cultural knowledge.

4. One has to look beyond movement to get at its meaning. ... The concepts embedded in movement are not necessarily evident in the movement itself. ...

5. Movement is always an immediate corporeal experience. The cultural knowledge that is embodied in movement can only be known via movement.

Sklar's model provides a broader framework for approaching movement, particularly through ethnographic research, and combining it with other kinds of knowledge about history, politics, culture, and society. Her final point about knowing movement via movement provides the key 
to why body movement, as noted by Jane Desmond, "remains a greatly undervalued and undertheorized arena of bodily discourse. Its practice and its scholarship are, with rare exception, marginalized within the academy" (Desmond I998, I 54).

Scholars, particularly of the Pacific, and including those who study music and performance, are not usually known for their dancing skills. ${ }^{8}$ This is not surprising, but given the iconic status of dance in the Pacific region, and noting Sklar's framework, one wonders what the potential might be for expanding research training in Oceania beyond the standard theoretical and other scholarly modes of engaging and studying Pacific cultures. Moreover, for those who do intensive "participant observation," how much do their final scholarly products reflect their very embodied modes of "participation"? In Pacific studies, in both its disciplinary and interdisciplinary manifestations, the performing arts are rarely combined with anthropology, history, cultural studies, economics, or political science for any kind of corporeally focused mode of inquiry or analysis. ${ }^{9}$

The cohort of Pacific dance scholars, including anthropologists, ethnomusicologists, and ethnologists, grows very slowly indeed. There are more researchers who focus on music with the word "dance" only added, for example, to the Study Group on the Musics of Oceania-now Music and Dance in Oceania, a working group of the International Council for Traditional Music-in 2005. By contrast, an international conference I coconvened with Sean Mallon and April Henderson in Wellington in 2005 titled "Culture Moves! Dance in Oceania from Hiva to Hip Hop" focused entirely on Pacific dance and covered the whole range of forms, from what people describe as "traditional" to contemporary and street dance. The lineup featured scholars such as Adrienne Kaeppler and Amy Ku'uleialoha Stillman, as well as contemporary dance company directors, including Neil Ieremia and Lemi Ponifasio (see Culture Moves! 2005). Moreover, scholars, directors, arts agencies representatives, community members, and dancers shared one stage with discussions and presentations followed immediately by long nights of diverse performances from all regions of the Pacific. The economic, political, social, historical, and embodied stakes of dance for Pacific Islanders were clearly highlighted in the discussions.

A recent and most welcome contribution to the literature is Kalissa Alexeyeff's ethnography, Dancing from the Heart (2009), which weaves together anthropological, historical, and political analyses of movement, gender, and globalization in the Cook Islands and approaches dance as social and political action. Her work provides an opportunity for fur- 
ther discussion of the creation of a "Pacific dance studies" space in the academy.

\section{A Thing of THE LAND}

In a recent book chapter on dance in Oceania (Teaiwa 2008), I highlighted a revealing piece in Arthur Grimble's authoritative collection, Tungaru Traditions, called “A Discourse on I-Kiribati Dancing," or the ruoia (I989, 3 I4-333). Much of this short piece is devoted to arguing against the colonial administration's and the Protestant Church's moves to ban dancing in the villages (also see Balme 2007 and Alexeyeff 2009). In an editorial footnote to Grimble's piece, the late H E Maude wrote: "Once again the ruoia [and] the easily learnt batere [popular dances derived from Ellice Islands patele] became immensely popular pastimes throughout the Gilberts, and it was soon obvious that should any further attempt be made to prohibit dancing [by] church adherents it would be the number of Christians rather than the number of dancers that would decline" (Grimble 1989, 333).

Grimble's writing underscores the absolute centrality of dance, but Maude was mistaken in describing the art form as merely a pastime. Few would disagree that dance is one of the most important expressions of I-Kiribati culture. Mary Elizabeth Lawson's I989 PhD study of I-Kiribati music and dance underscores this reality. She wrote about how I-Kiribati often say that a reason for the continued significance of Kiribati performance in their culture, and why it is so moving for them, is that it is "bai n abara" (a thing of our land), or "bai ni Kiribati" (a thing of Kiribati). Dance is something that originated with and was passed down from the bakatibu (ancestors) (Lawson I989, 79). Her study explores the profound significance of dance to the Kiribati sense of identity and more importantly grounds it in the land, a highly limited resource in this atoll nation. Performances of Kiribati dance beyond the shores of its thirty-three islands thus take on meaning as extensions of that land and emplaced identity. Moreover, the concept of te aba, or land, in the Kiribati language spoken by both I-Kiribati and Banabans unites the body of the land with the bodies of the people, as in most Pacific societies.

Lawson's work can be read with Elfriede Hermann and Wolfgang Kempf's 2005 analysis of Banaban dance theater on Rabi in Fiji to contextualize the development and transformation of Banaban dance after their displacement from the Gilbert Islands colony. Kempf and Hermann's work is significant in that it is one of the few studies that explore land 
relationships and ethnicities in Fiji through the performing arts (see also Teaiwa 2002). Their analysis accurately portrays the politics of Banaban performance as both a means of remembering and reviving a lost homeland and of carving out a physical, social, and political space for themselves on a new island in multicultural Fiji. They also highlighted the ongoing agenda to construct ethnic difference through dance, quoting the former Rabi Council chairman, Tebuke Rotan, who led the charge against the British government in the I970s that is referred to in this article's epigraph. Rotan explained, "The first time in history we Banabans make our own dance. We can call it our own. On Rabi. On Banaba, we always copied the Gilbertese dance ... we made nothing of our own. ... One of the main reasons for this dancing is to show to the world that we Banabans have our own culture" (Kempf and Hermann 2005, 375).

While Kempf and Hermann astutely tracked the narrative and political elements of Banaban dance theater, they did not extend their thesis on the relationships among performance, politics, history, and identity to Banaban choreography beyond a now iconic historical dance drama. The aspect of Banaban dance they analyzed in this drama was the narrative and choreographic sequence in a set repertoire of significant events constituting the publicly accepted version of "Banaban history."

This dance theatre is performed every I 5 December, commemorating the Banaban landing in Fiji on that day in 1945. The drama is a linear and often pantomimic sequence illustrating certain features of pre-mining Banaban culture, the arrival of Christianity, negotiations over land rights, Japanese occupation during World War II, dispersal to war camps and subsequent removal to Rabi, the shock of life in a strange new environment, and an appeal to God for help to survive in the new land. Once this drama has been presented and Banaban origins and struggles reinforced for the audience, performance groups usually present an array of nontheatrical dances. It is the choreographic elements in this style of dance that require closer examination.

\section{Bodies Constructing Difference}

Akhil Gupta and James Ferguson reassessed the project of anthropology in these terms: "We are interested less in establishing a dialogic relation between geographically distinct societies than in exploring the processes of production of difference in a world of culturally, socially, and economically interconnected and interdependent spaces" (1997, 43; ital- 
ics in original). It is the production of difference between I-Kiribati and Banabans over time and specifically how these differences and the underlying connections are negotiated by dancing bodies that I would now like to explore.

The tensions between these two groups were personally difficult for me to research because, like many Banaban families, mine have ancestral roots in Kiribati. Both of my paternal grandparents were from Tabiteuea in Kiribati, and it was my great-great-grandmother Kieuea and her son Tenamo who were Banaban. While I had learned of some of these tensions from my father, who was chairman of the Rabi Council of Leaders between 1996 and 2000, I did not realize just how passionate the debates were in the I970s when Banabans sent back approximately sixty young men and women to occupy their island and reclaim it from the government of the Gilbert Islands. At the time, the Banabans were in the process of suing the British government and the company for breaching a contract to replant their trees and for overmining (see Kituai I982). ${ }^{10}$ The Banaban occupation resulted in the bombing of the mines and the arrest of a few of the young men by Gilbertese police. This period is forever seared in the memories of that generation of Banabans and represents a low point in Banaban-I-Kiribati relations.

The debates over kinship played out most intensely in the editorial section of the Fiji Times newspaper for much of that decade. Just one in a long string of accusations and insults, the following is an excerpt from a letter written in 1976 by the secretary of the Rabi Council of Leaders, Thomas Teai, to the Fiji Times editor:

Sir,

We would not mind if the I-Kiribati were to refer to us as "Our Banaban cousins" in the same way as the British refer to their "American cousins," a relationship that is not to be taken too literally. But the kinship that the I-Kiribati are so anxious to claim goes no deeper than that. Intermarriage between Banabans and I-Kiribati does not change the racial origin of the participants. An I-Kiribati marrying a Banaban remains an I-Kiribati just as a Fijian marrying a Tongan remains a Fijian. The Gilbert Islands statement mentions, rather puzzlingly, that when we Banabans came to live in Fiji after the war we brought I 52 I-Kiribati men with us. So what? They had been with us in Japanese captivity and we had shared many hardships. They asked us to take them to Rabi. That established sympathy and friendship. Nothing more. They remain I-Kiribati. They own no land on Rabi, as they would if they were Banabans. (Fiji Times, 9 Sept 1976) 
This letter was quickly followed by a letter from a young Teburoro Tito, who later became the president of Kiribati, asking Thomas Teai if he realized that his own grandmother was from Arorae in the Gilberts and reminding him that his I-Kiribati lands were waiting patiently for him to claim them. Another more humorous response came from an I-Kiribati man who asked the Banabans to wait patiently for the technology that would allow them to uproot Banaba from its central Pacific location and drag it I,600 miles across the seas to rest alongside Rabi Island in Fiji. Ironically, most of the two-and-a-half square miles of Banaba had already been uprooted by that time and, through the use of state-of-the-art technology, had been spread over the fields of Australia, New Zealand, and other distant lands. This is no laughing matter.

From the late I960s until the early I980s, Banaban nationalism was at its peak on both Rabi and Banaba. The Banabans wanted two things: independence from the colony of the Gilbert and Ellice Islands, and compensation from the British government and ВРС for the damages caused by the mining industry (see Teaiwa 2000, 2002). One of the major strategies for achieving independence was for Banabans to establish themselves as culturally and racially different from the I-Kiribati despite centuries of marriage and exchange between the islands. In the I970s, this incensed I-Kiribati politicians, who were themselves working toward independence from Britain and were relying on the reserve fund of income from phosphate shipments to seed and sustain their economic future (see Van Trease I993, 5-6; I 83-I 89). The I-Kiribati government vehemently claimed there were no differences at all between I-Kiribati and Banabans, and the Gilbertese public generally supported this stance, as illustrated by the cartoon on the next page (figure 3 ).

This is just a brief overview of the nature of Banaban and I-Kiribati tensions; in practice, a dynamic process of cultural exchange and intermarriage exists between Rabi and Kiribati. However, on Rabi, assertions of identity in private and public gatherings often take Banaban essence, or Banaban blood, to be the most important measure of identity and land rights (see Silverman I97I, I80-209). If a Banaban's I-Kiribati or other non-Banaban spouse wishes to speak in a public meeting, he or she will most likely be silenced. Martin Silverman recounted one particular example of this in which a meeting was held to sort out a Banaban genealogy and an I-Kiribati married to a Banaban woman tried to present his wife's lineage. He was told, "You have nothing to do with this matter; leave the meeting house!" (Silverman I971, 323-324). Today, I-Kiribati on Rabi 
are usually barred from actively participating in any position of responsibility or leadership even if they contribute their income or labor to the village or to the Rabi community. This is one of the things my father tried to change during his four-year chairmanship of the council. He would usually start a public meeting by inviting everyone to speak, and all the attendees understood that this was regardless of blood. I-Kiribati began to take an active role in village committees, but as soon as his term ended, they were once again barred from participation.

The Banaban Dancing Group was established in the I970s on both creative and political grounds. The idea was to perform an identity and culture that were distinct from those of the I-Kiribati. Up until the I96os, music and performance on Rabi had been dominated by I-Kiribati forms, with some Tuvaluan (Ellice Island) influences. In particular, the mostly I-Kiribati Catholic community, while not so vocal in politics, was strong in the area of cultural performance. They had developed string bands and singing groups that were increasingly popular across Rabi, attracting participation from the mostly Methodist Banaban groups.

During the lawsuit against the British government in the I970s, the

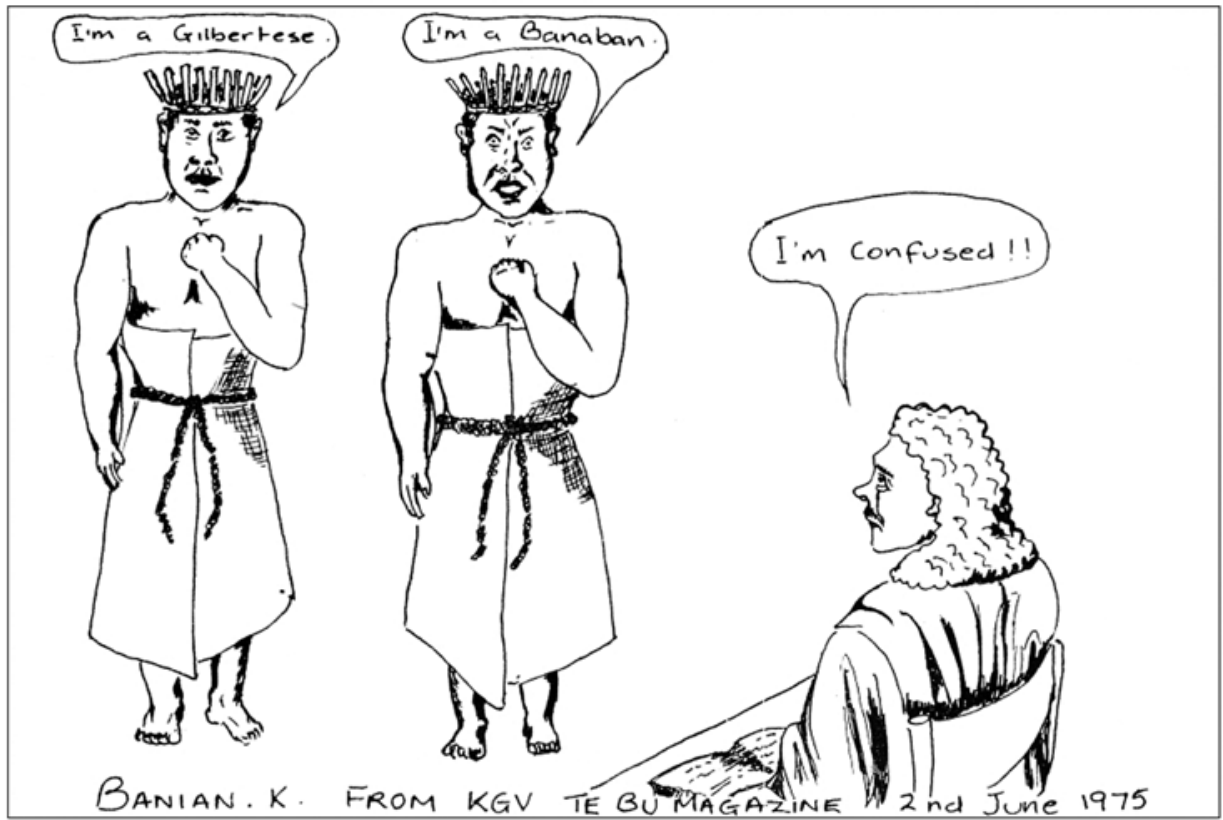

Figure 3 Cartoon drawn by a Gilbertese student of the King George V Secondary School in Te Bu Magazine, June 1975. 
Rabi Council of Leaders helped create a distinct Banaban Dancing Group as a kind of emblem for the people and their cause and most specifically to prove their difference from the Gilbertese (Kempf 2003). The dance troupe, as signaled in the epigraph to this article, symbolized a unique Banaban culture, different from I-Kiribati and lending validity to the movement for independence from the Gilbert Islands, which the Gilbertese government was passionately challenging. In his discussion of the politics of music and dance on Rabi, Kempf wrote, "Creating a representative dancing group, which performed a new dance style adept at blending into its program highly dramatic performances relating to Banaban culture and history, was thus one aspect of the Banaban political strategy to promote ethnic difference" $(2003,38)$.

The dancing group marched along with leaders of the Rabi community at a protest march in Suva (figure 4). Members of the dance group had previously toured the Pacific, performing at the opening of the Sydney Opera House in 1972 (Dean 1978,87 ). A few years before this trip, the Banaban dance costume was established under the directives of one of the event organizers, Beth Dean (now Beth Dean Carell), who strongly suggested that all costume materials be made of natural fibers rather than the beads, crepe paper, raffia, and ribbons that were popular on Rabi and in Kiribati.

The principle composer and director for the group was a man named Tawaka Tekenimatang, and from the beginning it was acknowledged that the new Banaban dance styles were deliberately constructed, rather than

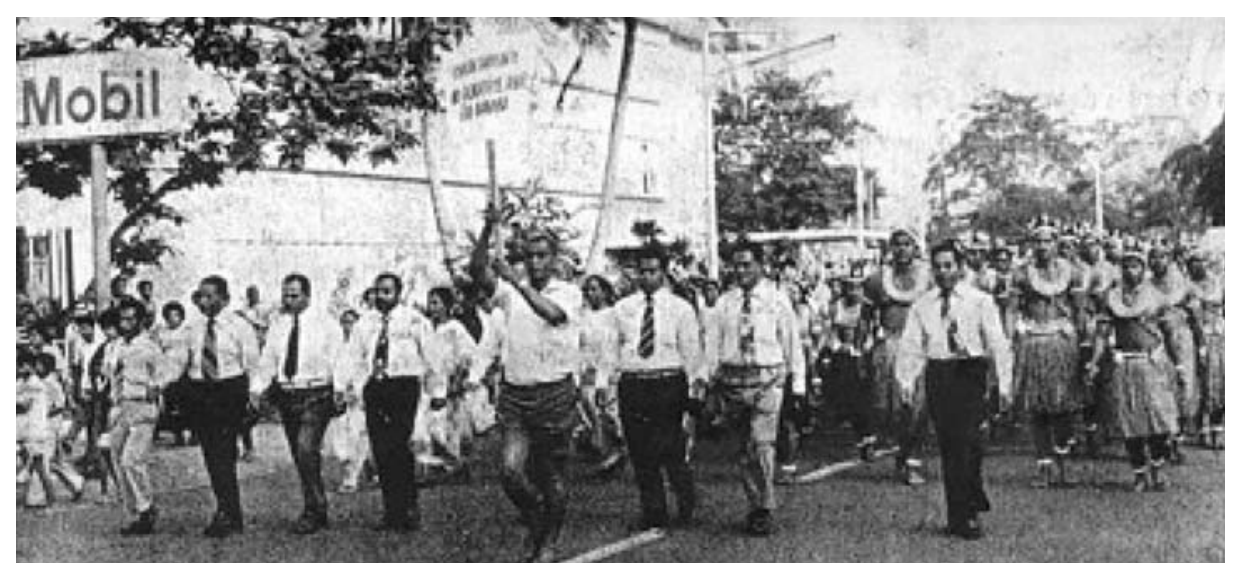

FIGURE 4 Banaban protest march in Suva. Undated clipping from the Fiji Times, circa 1976. 
"traditional." Beth Dean later wrote, "The Banaban people have, through an imaginative choreographer ... developed a style of dance of their very own" $(1978,62)$. She did not elaborate on why such a "dance of their very own" was required, but her professional assessment of the new dances was that they worked. She wrote, "It is the lovely restraint of understatement that makes Banaban dance the very special experience it is. They have created their own style out of many ingredients" (Carell 2005, 242).

It is important to explain that Tekenimatang was not a choreographer in the Western sense; rather, he was te tia kainikamaen, a master composer in the ancient sense of the term. The composer is the most important figure in a performance group, and Tekenimatang received divine inspiration for his music. A dancer in the first group of professional Banaban performers described how the group's movements were created and reflected on what she called "the traditional" and "the modern" elements: "Tawaka was a serious man, very strict and very attentive to detail, and he was able to use our natural way of dancing in his compositions. He composed songs and taught them to us, but the four older women in the group set the actions. Two of them looked after the more traditional aspects, and two set the more modern actions. You have to do some traditional things in your life and you have to have some modern things. It's the same in a dance" (Borerei 2005, II6).

Kempf wrote that the power-knowledge used by kainikamaen on Rabi for composition is very much an appropriation of Kiribati practices and that there is no documentation that such practices existed prior to mining (2003). I believe that the lack of documentation on composition and dance traditions is not evidence that the practice did not exist, and given the fact that Gilbertese migrated to the island centuries before mining began, there would have, of course, been an active exchange of culture and spiritual knowledge unique to each group. According to Kempf, however, Tekenimatang learned his kainikamaen knowledge from a phosphatemining worker from Maiana before the Banabans were moved to Rabi in I945 (Kempf 2003, 4I). Similarly, subsequent leaders of the Rabi Dancing Group and Te Kananraoi, created in the years after the Banaban Dancing Group was formed, also received their ritual knowledge from Kiribati sources. In all ways, then-spiritually, musically, and choreographicallyKiribati knowledge is a significant source of creativity and knowledge that Banaban artists weave with other forms.

One of the early popular features of the Banaban Dancing Group was the use of castanets. Tebuke Rotan, son of Rabi Chairman Rotan Tito and 
one of the men who led the Banaban suit against the British, purchased these in New York after being inspired by flamenco dancers in Barcelona. While castanets are rarely used today, they indicate just how open to possibility and outside influence Banaban dancing was despite the rhetorical stress on difference. According to Beth Dean (1978, 62), the sound of the castanets was replicated by using two pieces of hardwood clicked by groups of female dancers as they weaved in and out in lines that created different shapes, like "V" or "T." These weaving formations were among a series of new choreographies that broke with set Kiribati patterns and included a speeding up of Kiribati forms and rhythms as well as the incorporation of the popular Western twist, the Samoan taupati (a body percussion dance), the Tahitian tamure, and later, when the community had gained access to film and video, karate- and kung fu-inspired male styles.

At its very inception, Banaban dancing was an open-ended form, always ready to incorporate new movement, music, or materials. The use of the Western drum kit, for example, in combination with a sitting choir that is more characteristic of I-Kiribati and Tuvaluan performance, is another illustration of this. Martin Silverman once wrote that Banaban culture consists of a "have your cake and eat it too" logic (I97 I, I 5), and this is very apparent in the area of dance. Banabans have developed something so "unique" and creative that it draws not just from Kiribati and the Pacific but from around the world, and yet it is still claimed as uniquely "Banaban." Politically, "difference" is the goal, but in practice, connection, borrowing, and incorporation are the norms.

\section{The People Who Dance Like This}

In her study of the kinesthetic and visual symbolism of dance in Cebu City in the Philippines, Sally Ann Ness asked, "what ordinary and/or extraordinary meaning did the sinulog [a Cebu ritual dance] choreographic practices possess for their neocolonial culture bearers?" (I992, 2). In Body, Movement, Culture (I992), Ness produced a brilliant ethnography that places the moving body at the center of her theory and method. Dance becomes a choreographic instance in which the invisible links between past and present, ordinary life and extraordinary performance, memory and lived experience, converge and are illuminated (see also Farnell 1994).

Similarly, Rabi dance can be viewed as a reflection and repository of a specific history and of contemporary cultural and political strategies. Attention to performance thus begs new research questions that link dance 
directly to historical, social, and political aspects of Banaban society. We could ask, for example, what does it mean for Banaban choreographers to build on, speed up, break, bend, and twist I-Kiribati dance forms? What does it mean for Banaban bodies to perform the result of this transformation every year on I 5 December under the rubric "Banaban dance"?

With basic Kiribati and Banaban dance literacy it is possible to see what Banaban choreographers have done to the underlying I-Kiribati dance vocabulary. The latter is based on an abstraction of the various atoll creatures, on fishing and gathering techniques, and on the frigate bird motif, where arms glide between specific and rigidly held positions, and where the head and eyes dart between these same fixed points. The legs and feet are usually close together; the feet move the body forward and back with small steps, sometimes slow, sometimes rapid; and the torso is held in the same position throughout. The most dynamic movements in Kiribati dance are in the arms and heads for men and women, and in the hips for women in the buki.

The Kiribati dancing body is held purposefully, the movement vocabulary is precise, and generally there is little room for choreographic improvisation. ${ }^{11}$ In disciplinary terms, it is similar to ballet because of its set structure and a shared understanding between audience and performers of what constitutes virtuosity. Banaban choreographers and dancers, however, have loosened and unraveled the entire structure, opening it up for all kinds of choreographic possibilities. If we were to use Adrienne Kaeppler's more structuralist approach to movement (1972), we would say that Banabans have taken Gilbertese kinemes-the smallest units of meaningful movement, analogous to linguistic phonemes—and combined them with other movement units from other movement systems to create something "Banaban."

Similarly, Banaban musicians and singers took the Kiribati musical form-which normally begins with a quiet, slow, and measured melody and rhythm and gradually progresses by way of key modulations and tempo increases to a frenzied and deafening crescendo-and fixed it at the faster end of the spectrum. Heads, hands, torsos, hips, and feet move in multiple directions, one moment twisting, another bending. Legs lift off the ground, levels change regularly, in a few seconds the movements shift from something that looks like a Cook Islands 'ura to something more resembling Scottish country folk dance. However, Banaban dance still maintains the tension exhibited in Kiribati dance between the dancing body and the intensity of the choir and music. In both performance styles, 
dancers do not merely dance to the music; they work emotionally perpendicular to or against the music, resisting the increasing tempo lest they be swept away by its force.

On the surface, all of this increases the entertainment factor of the Banaban form and allows diverse audiences to appreciate it. Banaban dancing is so popular that it has now influenced the tempo and style of dancing back in Kiribati, and a few Banaban choreographers have established themselves there, transforming Kiribati dance practices, particularly in an age of accessible and mass media. This completes the circle of exchange in which Banabans acquired I-Kiribati kainikamaen knowledge, applied it to new compositions and choreographies, and then migrated to Kiribati where they shared their choreographic prowess and the new style they have developed.

So what does it mean for Banabans to speak the I-Kiribati language, to marry I-Kiribati, but to still vehemently maintain difference in their dancing and other expressions of identity? What does it mean for a Banaban child to be raised dancing te bino or te buki by her I-Kiribati grandmother and then to join the Banaban Dancing Group as a young adult and be taught to speed up and exaggerate the gliding movements, to twist her hips and knees all the way to the ground and back? It is becoming apparent on Rabi that what is reinforced or articulated in ongoing discourses of Banaban alterity, particularly in terms of their cultural or racial difference from I-Kiribati, is revealed as far more complex when observing the range of choreographies learned and performed by Banaban bodies.

To echo Jane Desmond's questions in her I998 critique of dance and cultural studies, how can we further our understanding of how Banaban social identities are signaled, formed, and negotiated through bodily movement? Addressing such questions helps our understanding of how Banabans continue to survive creatively, or choreographically, on Rabi despite their dislocation from Banaba and the loss of political sovereignty to Kiribati. It also addresses long-standing tensions around what constitutes authentic Banaban culture, tensions usually played out between the various generations, the most recent of which were born and raised on a volcanic island far from Banaba, surrounded by a Fijian culture that is greatly shaping contemporary Banaban society. People on Rabi are actively creating their culture from all possible sources, even as they politically maintain a timeless and unchanging Banaban identity or essence. Both innovation and continuity prevail. 
"Creation," anthropologist Edward Sapir aptly wrote, "is a bending of form to one's will" (1924, 4I8). In the introduction to Creativity/ Anthropology, Smadar Lavie, Kirin Narayan, and Renato Rosaldo stated, "Invention takes place within a field of culturally available possibilities, rather than being without precedent. It is as much a process of selection and recombination as one of thinking anew" (I993, 6). The authors described how creativity emerges from past traditions and moves beyond them and how the creative persona reshapes traditional forms. The circumstances of creativity thus always admit to contact, borrowing, and conflict. Regarded, then, as a field of creativity, the zones of interaction among and within cultures would "more closely resemble the overlapping strands of a rope than separate beads on a string" (Lavie, Narayan, and Rosaldo I993, 6).

Lavie, Narayan, and Rosaldo's analysis of "creativity" and "invention" is apt for the Banaban situation. "Eruptions of creativity within cultural performances comment upon, as much as they reformulate, the dilemmas a society faces at a particular historical moment" (Lavie, Narayan, and Rosaldo I993, 6). For Banabans it was the literal loss of land through mining and a particularly charged cultural and political situation with the I-Kiribati people and government that gave rise to "Banaban dance" on

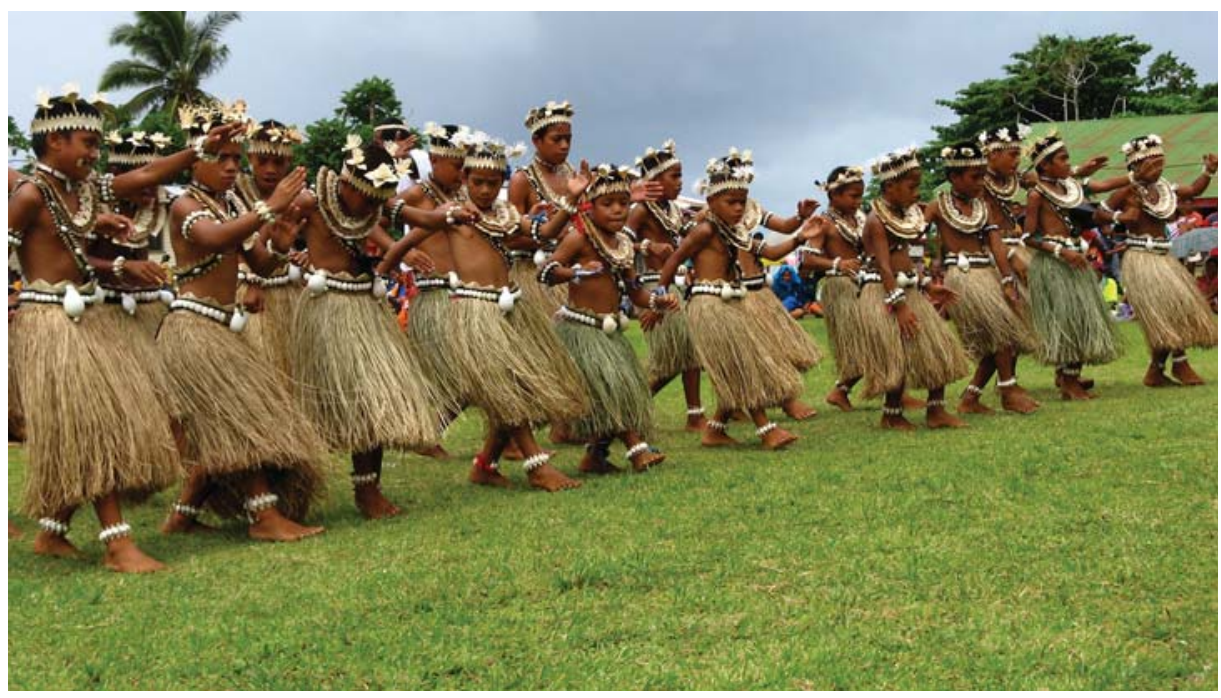

Figure 5 Banaban schoolboys dancing on I 5 December 2007 on Rabi. Photo by Nicholas Mortimer. 
Rabi in the late I96os. This new style is now recognized as an established and unique Pacific dance tradition (figure 5).

The creation of Banaban dance may have been an explicit political act, but the movements of Banaban dancers point to a larger and more fluid historical experience and interaction with other cultures and places. They are instrumental in creating a "unique" Banaban identity, but they are also pathways beyond an essentialist Banaban identity. To claim Banaba as the only true home and then perform "Banabaness" through a mixture of forms, sounds, and choreographies from all over the world seems contradictory. But Ness stressed what can be learned from moving bodies thus:

When dancing you are not an ordinary instrument, like a towel or a knife, but you are aware of being extraordinarily instrumental all the same. Your body becomes the key to relating a tremendous imaginary reserve of purposeful instances of self-conduct, in the most ideal terms conceivable. The imagined reservoir itself, which is exposed and generated by this activity, is both a cultural and choreographic construct. (Ness I992, Io)

Ness's reservoir is of a human being's habitus or lifeway, a reservoir of memory, whose depth and surface, she wrote, may be grasped in its full significance perhaps "only via extraordinary, 'metafunctional' practices, such as dance" (I992, 2). Banaban dancing thus incorporates movements from all the cultures and places-the reservoir-that the community has encountered over centuries of contact with Gilbertese, Hawaiians, Samoans, Cook Islanders, Tahitians, Ellice Islanders, Kosraeans, and, particularly in the twentieth century and because of the phosphate mining industry, with Fijians, Japanese, Chinese, Australians, New Zealanders, British, and others. Moreover, it is potentially the reservoir of all encounters and literal cross-fertilizations between Banaban land and the communities, landscapes, and various agricultural products that have grown and developed as a result of phosphate fertilizer made of Banaban te aba, that is, the land and people (see Teaiwa 2005a).

If history is, as Wendt imagined, a reflection of memory and remembering, then Banabans have chosen to publicly remember and verbally express their past selectively, but their dancing bodies belie this process. In the I 5 December village dance competition in 2007, the Rabi Council gave a directive to all competitors that the repertoire of each group had to reflect the three main influences on Banaba culture: Fijian, Tuvaluan, ${ }^{12}$ and Banaban music and dance. I-Kiribati culture was deliberately not included as a significant influence, but the echo of I-Kiribati and other 
movement vocabularies still reverberates through the dancing Rabi bodies. The Catholic communities on Rabi continue to hold dance competitions in the I-Kiribati styles, parents and grandparents still teach children I-Kiribati dance, and these choreographies remain apparent as significant elements of Banaban dance.

Ann Cooper Albright explored the process of "choreographing difference" in her collection of essays of that title. She asked what it means to reinscribe history through one's body and what happens when the history of a body becomes the history of a people (Albright I997, I 50). In the case of Banaba, it is the history of an island that has become the history of a people. This includes Banaban bodies, as explained earlier, in terms of the double reference-land and body-in the indigenous concept of land, te aba, from which the word "Banaba" (the rock) comes. An experience of one of the members of the Banaban Dancing Group captures well this link between Banaban lands and bodies: "[I]n 1976 we went to Rotorua in New Zealand for the second South Pacific Arts Festival. While on a bus trip through the nearby countryside, we saw an aerial topdressing plane putting fertiliser onto a farm. The bus driver told us it was superphosphate from Ocean Island and that made us feel sad and stirred our hearts. It seems that some of Banaba is in New Zealand" (Borerei 2005, II6).

Wendt reflected on how postcolonial Samoan bodies in New Zealand bear the values, practices, and-through tatau (tattoo) designs on their bodies-motifs of both the ancient and the contemporary (Wendt I996). Appropriating his perspective, the postcolonial or post-mining Banaban body, while "tataued" with the patterns of ancient and contemporary corporeal expressions, freely incorporates whatever the multicultural nation of Fiji, the region, and the globe have to offer. While discursively rejecting most of its I-Kiribati roots, Banaban dance as a musical and choreographic phenomenon illustrates a journey of learning, accepting, negotiating, and transforming I-Kiribati and other knowledges, forces, forms, and identities over the last one hundred and ten years of a tumultuous history. In this way, Banabans continue to survive and thrive, passing on their songs and dances to the next generation of Rabi Islanders. A Rabi schoolgirl, Teitinikaeke Teitirake, reflected on the stakes of participating in Banaban dance:

The elders tell us that immature people cannot really join a dancing group and somehow that really discouraged me ... through many years of patient wait- 


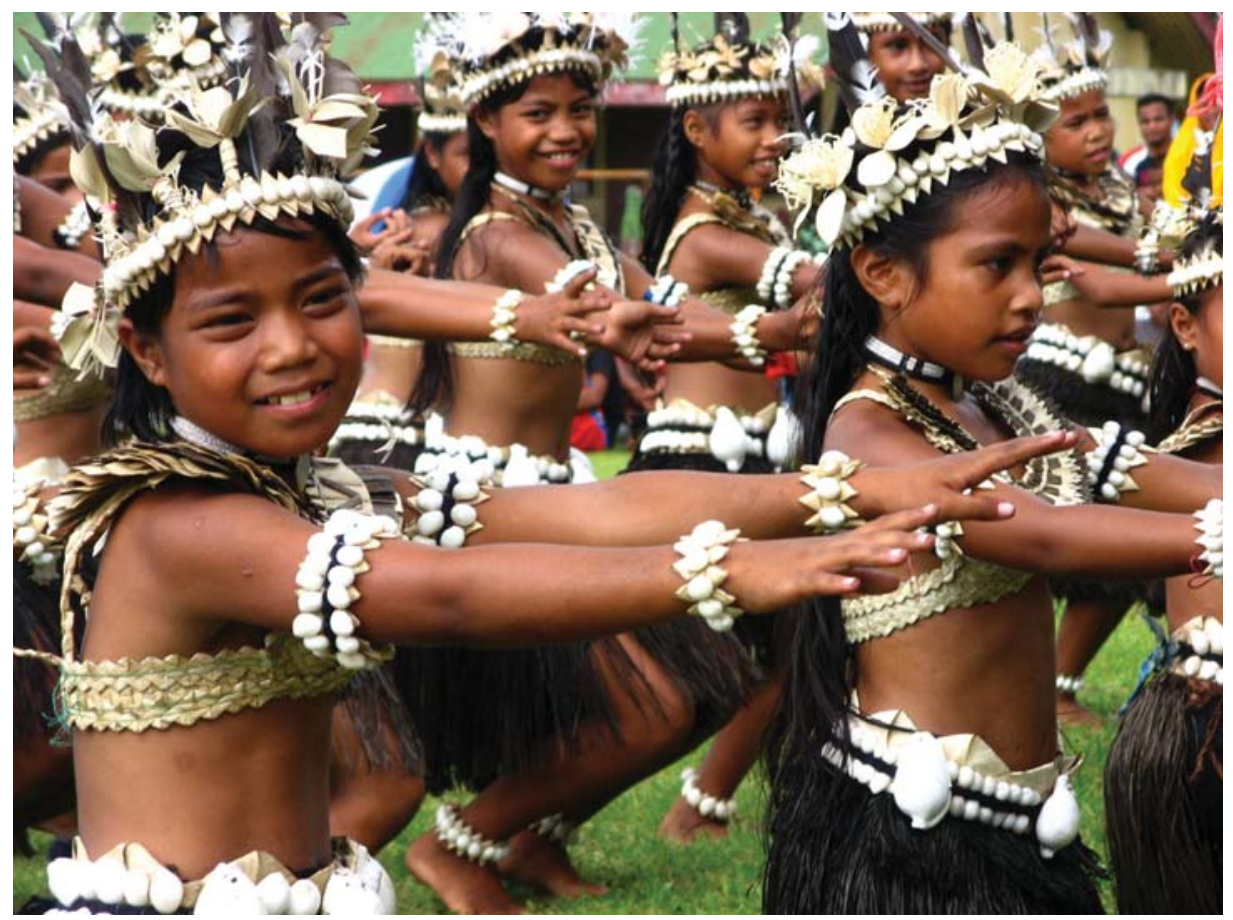

Figure 6 Banaban schoolgirls dancing on I 5 December 2007 on Rabi. Photo by Nicholas Mortimer.

ing ... I was accepted by the dancing group. . . . But then my parents thought I should go to a school study camp . . . and that meant I would not be able to attend the dance practices. I cried and cried because I so much wanted to do the dancing, more than anything else in my life. (Teitirake 2005, I 49-I 50)

Teitinikaeke's grandmother, Makin Corrie Tekenimatang-Tawaka Tekenimatang's wife, one of the original choreographers of the first Banaban Dancing Group, and likely one of the women referred to by Kaiao Borerei as an elder who set the actions-talked to the girl's parents and they decided to let her join the group. This was the first generation of youth dancers who were allowed to learn te karanga, a stick dance accompanied by complex and ancient chants and the only Banaban dance that is thought to be without Kiribati or regional influence. The experience of learning this and other dances clearly shaped Teitinikaeke's sense of Banaban identity (figure 6). 
In Jennifer Shennan and Makin Corrie Tekenimatang's edited collection, One and a Half Pacific Islands: Stories the Banaban People Tell of Themselves, Tekenimatang's granddaughter wrote:

I believe this dancing experience has had important effects on my life. I feel it has taught me to be more aware of and careful about what is involved in standing for my people. Perhaps most importantly it has given me a repertoire of stories to tell a future generation of Banabans. (Teitirake 2005, I 50 )

I would like to thank Margaret Jolly, Gary Kildea, and the late Greg Dening for their generous support of my work. Many thanks as well to my elder sister, Teresia Teaiwa, and mother-in-law, Nancy Mortimer, for early comments on this paper, and to two anonymous reviewers for their very helpful suggestions.

\section{Notes}

I The Gilbert Islands were so named by European explorers in I 820 after British Captain Thomas Gilbert, but the indigenous people knew them as "Tungaru." The Gilbert and Ellice Islands were administered as a protectorate of the British government from I 892 and became a colony in 1916. The Ellice Islands achieved independence first in 1976 and became "Tuvalu," so the Gilberts opted for "Kiribati," pronounced "Kiribas," which is the indigenous pronunciation of "Gilbert."

2 I discuss this as "homework" in Teaiwa 2005 a.

3 The Oceania Centre for Arts and Culture was founded by Professor Epeli Hau'ofa in 1997 at the University of the South Pacific. It was an independent center, with no formal training or accredited arts programs, and it welcomed artists of all walks of life. Eventually, clusters of dancers, visual artists, and musicians and composers emerged, and they collaborated on theatrical productions. Allan Alo became the resident choreographer and artistic director, and I was a regular collaborator during summer and Christmas breaks from university in the United States. Professor Hau'ofa passed away in early 2009, and today the Oceania Centre has been merged with Pacific studies at the university and is in the process of becoming fully institutionalized.

4 My research on Banaba (Teaiwa 2002) includes seven short visual studies on DVD covering Banaba, Tabiteuea, and Rabi in 2000, as well as historical footage of Banaba from the BPC archives. Video 7 is a montage of "Pate Pate" as it is danced across these islands, and in Honolulu and Canberra, by diverse groups of people. 
5 See Kondo I990 for a similar experience in a Japanese context.

6 Photographer and artist Mark Willie Chung generously duplicated all the archival images for me in Melbourne in 1999.

7 Sklar's approach also shaped a master's course I co-taught with Professor Judy Van Zile at the University of Hawai'i at Mānoa in 2006 in which we combined the Pacific Islands studies course "The Body and Pacific Studies" with "World Dance Cultures" in the Dance Department.

8 Notable exceptions include ethnomusicologists and dance ethnologists who are also dancers and dance instructors: Adrienne Kaeppler, Amy Ku'uleialoha Stillman, Jane Moulin, and Jennifer Shennan.

9 However, the University of Hawai'i at Mānoa's MA and PhD ethnomusicology programs, while focused on world music rather than dance per se, offer a rich slate of interdisciplinary study (see http://www.hawaii.edu/uhmmusic/degrees/MA _Ethno.htm).

Io There were two related actions under Tito vs Waddell representing the chairman of the Rabi Council, Rotan Tito, and the defendant, Her Royal Majesty's attorney general. The trial received widespread coverage in the British and Pacific media. What is fascinating is that the defendant was not the В РС or mining company but rather the Crown, which could thus only allow for a "moral" but not financial victory for the Banabans. The precedent of winning a lawsuit against a colonial government would have had significant international implications.

I I There are certain Kiribati dances, such as the taupati, that are versions of the Samoan fa'ataupati performed by both men and women in Kiribati. Strong genealogical relationships exist between the two countries, but this is mainly acknowledged in Kiribati and Banaban oral traditions, and not so much in Samoan.

I 2 The most recent Tuvaluan influence is from the island of Kioa, an hour's boat ride from Rabi. Vaitupu Islanders from Tuvalu (formerly the Ellice Islands) purchased Kioa in 1947 due to overcrowding in their home islands.

\section{References}

Albright, Ann Cooper

I997 Choreographing Difference: The Body and Identity in Contemporary Dance. Middletown, CT: Wesleyan University Press.

Alexeyeff, Kalissa

2009 Dancing from the Heart: Movement, Gender, and Cook Islands Globalization. Honolulu: University of Hawai'i Press.

Balme, Christopher

2007 Pacific Performances: Theatricality and Cross-Cultural Encounter in the South Seas. Basingstoke, uk: Palgrave Macmillan. 
Behar, Ruth, and Deborah A Gordon, editors

I995 Women Writing Culture. Berkeley: University of California Press.

Borerei, Kaiao

2005 Dancing and Massage. In One and a Half Pacific Islands: Stories the Banabans Tell of Themselves, edited by Jennifer Shennan and Makin Corrie Tekenimatang, I I6-I I 7. Wellington: Victoria University Press.

Carrell, Beth Dean

2005 Banaban Dance. In One and a Half Pacific Islands: Stories the Banabans Tell of Themselves, edited by Jennifer Shennan and Makin Corrie Tekenimatang, 239-242. Wellington: Victoria University Press.

Culture Moves!

2005 Culture Moves! Center for Pacific Islands Studies conference website. http://www.hawaii.edu/cpis/dance/index.htm [accessed 3 May 2OII]

Dean, Beth

I978 South Pacific Dance. Sydney: Pacific Publications.

Desmond, Jane C

I998 Embodying Difference: Issues in Dance and Cultural Studies. In The Routledge Dance Studies Reader, edited by Alexandra Carter, I 54I62. London: Routledge.

Farnell, Brenda $\mathrm{M}$

I994 Ethno-Graphics and the Moving Body. Man 29 (4): 929-974.

Foster, Susan Leigh, editor

I995 Choreographing History. Bloomington: Indiana University Press.

Grimble, Arthur

I989 Tungaru Traditions: Writings on the Atoll Culture of the Gilbert Islands. Pacific Islands Monograph Series 7. Honolulu: Center for Pacific Islands Studies and University of Hawai'i Press.

Gupta, Akhil, and James Ferguson

I997 Beyond "Culture": Space, Identity, and the Politics of Difference. In Culture, Power, Place: Explorations in Critical Anthropology, edited by Akhil Gupta and James Ferguson, 33-5I. Durham, NC: Duke University Press.

Kaeppler, Adrienne L

I972 Method and Theory in Analyzing Dance Structure with an Analysis of Tongan Dance. Ethnomusicology I6 (2): I73-2I7.

Kempf, Wolfgang

2003 "Songs Cannot Die": Ritual Composing and the Politics of Emplacement among the Resettled Banabans on Rabi Island in Fiji. The Journal of the Polynesian Society I I 2 (I): 33-64. 
Kempf, Wolfgang, and Elfriede Hermann

2005 Reconfigurations of Place and Ethnicity: Positionings, Performances and Politics of Relocated Banabans in Fiji. Oceania 75 (4): 368-386.

Kituai, August Ibrum Kumaniari

I982 An Example of Pacific Micro-nationalism: The Banaban Case. Bikmaus: A Journal of Papua New Guinea Affairs, Ideas and the Arts 3 (4): $3-48$.

Kondo, Dorinne

I990 Crafting Selves: Power, Gender, and Discourses of Identity in a Japanese Workplace. Chicago: University of Chicago Press.

Lavie, Smadar, Kirin Narayan, and Renato Rosaldo

I993 Creativity/Anthropology. Ithaca, NY: Cornell University Press.

Lawson, Mary Elizabeth

I989 Tradition, Change and Meaning in Kiribati Performance: An Ethnography of Music and Dance in a Micronesian Society. PhD thesis, Department of Music, Brown University.

Maude, H C, and H E Maude

I994 The Book of Banaba: From the Maude and Grimble Papers, and Published Works. Suva: Institute of Pacific Studies, University of the South Pacific.

Ness, Sally Ann

I992 Body, Movement, and Culture: Kinesthetic and Visual Symbolism in a Philippine Community. Philadelphia: University of Pennsylvania Press.

Sapir, Edward

I925 Culture, Genuine and Spurious. The American Journal of Sociology $29(4): 40 I-442$.

Shennan, Jennifer

I98I Approaches to the Study of Dance in Oceania. The Journal of the Polynesian Society 90 (2): 193-208.

Sigrah, Raobeia Ken, and Stacey M King

200I Te Rii ni Banaba. Suva: Institute of Pacific Studies, University of the South Pacific.

Silverman, Martin

I97I Disconcerting Issue: Meaning and Struggle in a Resettled Pacific Community. Chicago: University of Chicago Press.

Sklar, Deirdre

200I Five Premises for a Culturally Sensitive Approach to Dance. In Moving History/Dancing Cultures: A Dance History Reader, edited by Ann Dils and Ann Cooper Albright, 30-32. Middletown, ст: Wesleyan University Press. 
Teaiwa, Katerina Martina

2000 Banaban Island: Paying the Price for Other People's Development. In IWGIA, Journal of the International Work Group on Indigenous Affairs, edited by Nic Maclellan and Diana Vinding, 38-45. Denmark, I/2000.

2002 Visualising te Kainga, Dancing te Kainga: History and Culture Between Rabi, Banaba and Beyond. PhD dissertation, The Australian National University.

2004 Multi-Sited Methodologies: "Homework" in Australia, Fiji, and Kiribati. In Anthropologists in the Field: Cases in Participant Observation, edited by Lynne Hume and Jane Mulcock, 216-233. New York: Columbia University Press.

2005a Our Sea of Phosphate: The Diaspora of Ocean Island. In Indigenous Diasporas and Dislocations, edited by Graham Harvey and Charles D Thompson Jr, I69-I9I. Aldershot, UK: Ashgate Press.

2005b Teaiwa's Kainga. In One and a Half Pacific Islands: Stories the Banaban People Tell of Themselves, edited by Jennifer Shennan and Makin Corrie Tekenimatang, I20-I 23. Wellington: Victoria University Press.

2008 Salt Water Feet: The Flow of Dance in Oceania. In Deep Blue: Critical Reflections on Nature, Religion, and Water, edited by Sylvie Shaw and Andrew Francis, I07-I 25. Oakville, Cт: Equinox.

Teaiwa, Katerina Martina, editor

2007 Indigenous Encounters: Reflections on Relations Between People in the Pacific. Occasional Paper 43. Honolulu: Center for Pacific Islands Studies, University of Hawai'i at Mānoa.

Teitirake, Teitinikaeke

2005 My Dancing Experience. In One and a Half Pacific Islands: Stories the Banaban People Tell of Themselves, edited by Jennifer Shennan and Makin Corrie Tekenimatang, I49-I5O. Wellington: Victoria University Press.

Van Trease, Howard

I993 Atoll Politics: The Republic of Kiribati. Christchurch: Macmillan Brown Centre for Pacific Studies, University of Canterbury; Suva: Institute of Pacific Studies, University of the South Pacific.

Wendt, Albert

I987 Novelists and Historians and the Art of Remembering. In Class and Culture in the South Pacific, edited by Antony Hooper and others, 78-9г. Suva: University of the South Pacific; Auckland: University of Auckland.

I996 Tatauing the Post-Colonial Body. Span 42/43 (April-October): I 5-29. 
Williams, Maslyn, and Barrie Macdonald

I985 The Phosphateers: A History of the British Phosphate Commissioners and the Christmas Island Phosphate Commission. Melbourne: Melbourne University Press.

\section{Abstract}

This article discusses Banaban choreography as an expression of historical and postcolonial identities and, more specifically, relations between Banabans and I-Kiribati in terms of what I understand as the Banaban production of difference through dance. This process is shaped by a strategic approach to representing and reconstructing the past and kinship. I explore some of the tensions around history, kinship, and performance that resulted from the impact of phosphate mining and eventual displacement of Banabans from the Gilbert and Ellice Islands Colony (now Kiribati and Tuvalu) to Rabi in Fiji. I also discuss how this research opens up possibilities for a more corporeal approach to Pacific studies.

KEYWORDS: Banaba, Kiribati, Rabi, history, dance, body, identity 